\title{
Cytochrome P450 Metabolism of Betel Quid-Derived Compounds: Implications for the Development of Prevention Strategies for Oral and Pharyngeal Cancers
}

\author{
Che-Yi Lin, ${ }^{1}$ Tien-Szu Pan, ${ }^{2}$ Chun-Chan Ting, ${ }^{3,4}$ Shih-Shin Liang, ${ }^{5,6}$ \\ Shu-Hung Huang, ${ }^{7,8}$ Hsiu-Yueh Liu, ${ }^{3,9}$ Edward Cheng-Chuan Ko, ${ }^{3,10,11}$ \\ Chung-Wei Wu, ${ }^{10}$ Jen-Yang Tang, ${ }^{12,13,14}$ and Ping-Ho Chen ${ }^{3,14}$ \\ ${ }^{1}$ Department of Oral and Maxillofacial Surgery, Chi Mei Hospital, Liouying 736, Taiwan \\ ${ }^{2}$ Department of Electronic Engineering, National Kaohsiung University of Applied Sciences, \\ Kaohsiung 807, Taiwan \\ ${ }^{3}$ School of Dentistry, College of Dental Medicine, Kaohsiung Medical University, Kaohsiung 807, Taiwan \\ ${ }^{4}$ Department of Periodontology, School of Dentistry, Aichi Gakuin University, Nagoya 464-8651, Japan \\ ${ }^{5}$ Department of Biotechnology, Kaohsiung Medical University, Kaohsiung 807, Taiwan \\ ${ }^{6}$ Center for Resources, Research and Development, Kaohsiung Medical University, Kaohsiung 807, Taiwan \\ ${ }^{7}$ Graduate Institute of Medicine, College of Medicine, Kaohsiung Medical University, Kaohsiung 807, Taiwan \\ ${ }^{8}$ Division of Plastic Surgery, Department of Surgery, Kaohsiung Medical University Hospital, \\ Kaohsiung Medical University, Kaohsiung 807, Taiwan \\ ${ }^{9}$ Department of Dental Technology, Shu Zen College of Medicine and Management, Kaohsiung 807, Taiwan \\ ${ }^{10}$ Division of Oral and Maxillofacial Surgery, Kaohsiung Medical University Hospital, Kaohsiung 807, Taiwan \\ ${ }^{11}$ Departments of Cartilage and Bone Regeneration (Fujisoft), Graduate School of Medicine, The University of Tokyo, \\ Tokyo 113-8655, Japan \\ ${ }^{12}$ Department of Radiation Oncology, Faculty of Medicine, College of Medicine, Kaohsiung Medical University, \\ Kaohsiung 807, Taiwan \\ ${ }^{13}$ Department of Radiation Oncology, Kaohsiung Medical University Hospital, Kaohsiung 807, Taiwan \\ ${ }^{14}$ Cancer Center, Kaohsiung Medical University Hospital, Kaohsiung Medical University, Kaohsiung 807, Taiwan
}

Correspondence should be addressed to Jen-Yang Tang; reyata@kmu.edu.tw and Ping-Ho Chen; phchenkmu@gmail.com

Received 22 April 2013; Accepted 20 May 2013

Academic Editors: H.-W. Chang, L.-Y. Chuang, S. Guleria, and S. Yasmin

Copyright (C) 2013 Che-Yi Lin et al. This is an open access article distributed under the Creative Commons Attribution License, which permits unrestricted use, distribution, and reproduction in any medium, provided the original work is properly cited.

Betel quid (BQ) products, with or without tobacco, have been classified by the International Agency for Research on Cancer (IARC) as group I human carcinogens that are associated with an elevated risk of oral potentially malignant disorders (OPMDs) and cancers of the oral cavity and pharynx. There are estimated 600 million BQ users worldwide. In Taiwan alone there are 2 million habitual users (approximately $10 \%$ of the population). Oral and pharyngeal cancers result from interactions between genes and environmental factors (BQ exposure). Cytochrome p450 (CYP) families are implicated in the metabolic activation of BQand areca nut-specific nitrosamines. In this review, we summarize the current knowledge base regarding CYP genetic variants and related oral disorders. In clinical applications, we focus on cancers of the oral cavity and pharynx and OPMDs associated with CYP gene polymorphisms, including CYP1A1, CYP2A6, CYP2E1, and CYP26B1. Our discussion of CYP polymorphisms provides insight into the importance of screening tests in OPMDs patients for the prevention of oral and pharyngeal cancers. Future studies will establish a strong foundation for the development of chemoprevention strategies, polymorphism-based clinical diagnostic tools (e.g., specific single-nucleotide polymorphism (SNP) "barcodes"), and effective treatments for BQ-related oral disorders. 


\section{Introduction}

Oral and pharyngeal cancers are some of the most common cancers worldwide [1]. Taiwan is a hyperendemic area for oral and pharyngeal cancers [2]. In 2010, the age-standardized incidence rate adjusted by 2000 years world population (ASRW) of oral and pharyngeal cancers was 40.56 per 100000 Taiwanese males and was ranked the fourth most prevalent cancer in Taiwan [3]. The ASRW of oral and pharyngeal cancers among Taiwanese males was also ranked one of the highest worldwide [2].

Oral submucous fibrosis (OSF), leukoplakia, erythroplakia, and lichen planus are a group of oral potentially malignant disorders (OPMDs) thought to be linked to the development of oral and pharyngeal cancers [4,5]. Cases of oral and pharyngeal cancers are concentrated in Southeast Asia, where betel quid (BQ) chewing is prevalent [2]. Habitual BQ chewing is associated with an increased risk of oral and pharyngeal cancers and OPMDs [5-9]. Ko et al. demonstrated a significant association between BQ chewing without tobacco and the incidence of oral cancer [6]. In addition, BQ chewing is a major risk factor for OPMDs such as oral leukoplakia and OSF, and cigarette smoking was shown to have a modifying effect on chewing, based on an additiveinteraction model in oral leukoplakia patients [7].

The fourth most frequently consumed psychoactive substance worldwide after caffeine, nicotine, and alcohol is BQ, a masticatory mixture that combines the areca nut (AN), betel leaf, slaked lime, and various local flavorings [10]. Approximately $10 \%$ of the global population (approximately 600 million users) chew some form of BQ, primarily in the IndoPakistan subcontinent, South and Southeast Asia, and the South Pacific islands, and a large number of South Asian immigrants to the United Kingdom, Africa, Australia, and the United States are also BQ chewers [10-12]. In Taiwan, chewing BQ is a popular habit, particularly among males, with approximately 2 million regular users [13]. In a previous study, we found that male Taiwanese oral and pharyngeal cancer patients with a history of high-frequency BQ use had poor survival $[14,15]$.

By 2004, the International Agency for Research on Cancer (IARC) declared that BQ without tobacco is carcinogenic to humans (group 1) and increases the risk of oral cancer [16]. Although the masticatory practices and ingredients in $\mathrm{BQ}$ differ in different regions of the world, the $\mathrm{AN}$ is a major component of BQ worldwide, and the IARC has reported that $\mathrm{AN}$ alone is a group 1 carcinogen in humans. In the presence of slaked lime, the most abundant alkaloid of $\mathrm{AN}$, arecoline, is hydrolyzed to arecaidine during the chewing process [17]. Arecoline has been shown to be cytotoxic to mammalian cells in vivo and in vitro [18-20]. In vitro studies the mutagenicity and genotoxicity of arecoline and arecaidine have been examined primarily in short-term experiments [21]. However, in carcinogenicity studies in animals, the IARC (2004) reported that evidence indicating that arecoline may cause cancer is limited, but inadequate evidence for the carcinogenicity of arecaidine [16].
In general, exposure to $\mathrm{AN}$-derived carcinogens, particularly the alkaloids and the AN-derived $N$-nitrosamines, increases the risk of OPMDs and cancers of the oral cavity and pharynx in BQ chewers. Cytochrome P450 (CYP) enzymes are monooxygenases that catalyze many reactions involving carcinogens [22, 23]. During phase I metabolism, CYP families play important roles in detoxifying AN-derived compounds, such as arecoline [24], and are involved in the metabolic activation of arecoline-related $N$-nitrosamines [25]. A previous study suggested that arecaidine and three $N$ oxide metabolites are generated by the CYP enzyme system [26].

Environmental carcinogens and genetic polymorphisms, either separately or jointly, play an important role in the occurrence of oral and pharyngeal cancers. Environmental factors, such as alcohol use, BQ chewing, and cigarette smoking, were significantly associated with the risk of oral and pharyngeal cancers and OPMDs, and a synergistic effect among the use of these substances was also observed $[6,7$, 16]. The interactions of environmental and genetic factors in the tumorigenesis of oral and pharyngeal cancers have been shown to be affected by various CYP enzyme-mediated metabolic processes [27-30].

Several studies have indicated that CYP polymorphisms affect the metabolism of tobacco-derived carcinogens and the risk of oral cancer [31-33]. However, reports of the risk of oral and pharyngeal cancers and OPMDs associated with AN-derived carcinogens are scant. Our review focuses on the role of the CYP enzyme-mediated metabolism in OPMDs and oral and pharyngeal cancers among BQ users and evaluates emerging data that potentially implicate arecolineand arecoline-derived $N$-nitrosamines in tumorigenesis. The effects of CYP polymorphisms are worthy of investigation to further understand the role of genetic factors in susceptibility to OPMDS and cancers of the oral cavity and pharynx and to aid the development of prevention strategies for cancers related to BQ use.

\section{AN-Derived $N$-Nitrosamines}

2.1. Carcinogenicity of $N$-Nitrosamines In Vitro. The chewing of $\mathrm{AN}$ is believed to produce carcinogenic $N$-nitrosamines. Arecoline is the major compound of AN. The $N$-nitrosation of arecoline has been shown to form $N$-nitrosoguvacoline (NGL), 3-methylnitrosaminopropionaldehyde (MNPA), and 3-methylnitrosaminopropionitrile (MNPN) in vitro [34]. Based on studies of Salmonella typhimurium YG7108, CYP2A6 was found to be the most efficient activator of MNPN, followed by CYP1A1, and NGL was activated by CYP2A6. The genotoxicity of NGL was observed to be substantially lower than that of MNPN or MNPA [35]. Thus, that the human CYP2A6 gene may play an important role in the mutagenic activation of AN-related $N$-nitrosamines has been suggested [35]. Studies on rodents have shown that MNPN, MNPA, and NGL are carcinogenic. In carcinogenicity studies on animals, the IARC (2004) determined that evidence of MNPN carcinogenicity is sufficient [16]. The carcinogenicity 
of MNPN may be caused by DNA methylation, which has been observed in rats treated with MNPN $[21,36]$.

\subsection{Endogenous Nitrosation and N-Nitrosamines Carcino-} genicity. Endogenous nitrosation occurs during $\mathrm{BQ}$ chewing, exposing BQ chewers to four $N$-nitrosamines derived from arecoline [37]. These AN (arecoline)-derived $N$-nitrosamines include MNPN, MNPA, NG, and $N$-nitrosoguvacine (NGC). These arecoline-derived $\mathrm{N}$-nitrosamines are undetectable in the AN before chewing and are formed by the endogenous nitrosation of arecoline. Table 1 lists the maximum levels of NGL (142 ng/mL), NGC (26.6 ng/mL), and MNPN $(11.4 \mathrm{ng} / \mathrm{mL})$ in the saliva during BQ chewing without tobacco.

Many BQ chewers often swallow the quid juice, which contains the precursors of the nitrosamines. The $\mathrm{pH}$ of stomach acid likely facilitates the nitrosation of secondary and tertiary amines from the quid. A modified $N$-nitrosoproline test showed that the urinary levels of $N$-nitrosoproline, an endogenous nitrosation marker, are 2.4- to 6.5-fold higher in BQ chewers, with or without tobacco, compared to nonchewers $[42,43]$. Urinalysis of Syrian hamsters fed AN and a nitrite source detected NGL and its metabolite, $\mathrm{N}$-nitrosonipecotic acid [44, 45], indicating that exposure to nitrosamine carcinogens formed by endogenous nitrosation is likely higher among BQ chewers who swallow the BQ juice [46]. Several case-control studies have also indicated that swallowing the BQ juice is associated with a significant increase in the risk of oral cancer $[6,47,48]$.

2.3. CYP1A1-Mediated Metabolism of N-Nitrosamines. In a study of S. typhimurium YG7108, CYP1A1 was the second most efficient activator of MNPN, after CYP2A6, and MNPA activation was catalyzed to a lesser extent by CYP1A1 [35]. Previous studies have demonstrated that CYP1A1 polymorphisms are associated with susceptibility to tobacco-related oral cancers [31-33, 49,50]. Studies of the association between CYP1A1 polymorphisms and BQ-related oral cancers are scant.

Kao et al. found that people with the CYPIA1 Exon 7 polymorphism G/G genotype (val/val) are susceptible to BQ-related oral cancer and OPMDs [29]. They found that people who have the G/G and A/G (ile/val) genotype have significantly higher rates $(P<.0001)$ of oral cancer $(7.6 \%$ and $79.2 \%$, resp.) and OPMDs (10\% and $68.3 \%$, resp.) than controls (1.4\% and $53.4 \%$, resp.). Kao et al. calculated odds ratios for the development of oral cancer of 18.86 and 5.08 for those with the G/G (95\% CI, 3.61-98.52) or A/G (95\% CI, 2.64-9.76) genotype of CYPIA1, respectively, and also reported odds ratios for the development of OPMDs of 15.23 and 2.67 for those with the G/G (95\% CI, 2.76-83.98) or A/G (95\% CI, 1.32-5.40) genotype, respectively. These novel findings indicated that people with the $\mathrm{G}$ (val) allele may have an earlier onset age of oral cancer [29]. Another study showed that people with the CYP1A1 $\mathrm{m} 2$ polymorphism within the $\mathrm{NcoI}$ restriction site $(-/-)$ or the CYP1A1 $\mathrm{ml}$ polymorphism at the MspI site (+/-) and (-/-) had a significantly higher risk of oral submucous fibrosis $(\mathrm{OR}=8.25$; $95 \% \mathrm{CI}, 4.31-15.80$;
$\mathrm{OR}=2.88 ; 95 \% \mathrm{CI}, 1.57-5.24$; and $\mathrm{OR}=3.16 ; 95 \% \mathrm{CI}, 1.10-$ 9.04, resp.) [51].

2.4. The N-Nitrosamine-Metabolizing CYP2A6 Gene. Based on previous studies, we conclude that human CYP2A and CYP2E subfamily members play important roles in the metabolic activation of arecoline-related $N$-nitrosamines [52-54]. Located on human chromosome 19, the CYP2A6 gene consists of 350 kilobases located at 19q 12-19q 13.2 [55-57]. Thirteen alleles of the CYP2A6 gene have been identified (CYP2A6* 1 through CYP2A6 ${ }^{*} 11$ and CYP2A6 ${ }^{*} 1 \times$ 2; Table 2). The $C Y P 2 A 6^{*} 1$ allele has 2 forms, $C Y P 2 A 6^{*} 1 A$ and $C Y P 2 A 6^{*} 1 B$, that produce a gene conversion with the CYP2A7 gene in the $3^{\prime}$-untranslated region [58] and exhibit similar enzyme activity [58]. The CYP2A6* $2, C Y P 2 A 6^{*} 3$,

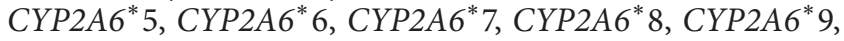
$C Y P 2 A 6^{*} 10$, and $C Y P 2 A 6^{*} 11$ genetic variants contain a different point mutation. In addition, the $C Y P 2 A 6^{*} 10$ variant contributes to variations in $C Y P 2 A 6^{*} 7$ and $C Y P 2 A 6^{*} 8$. The existence of $C Y P 2 A 6^{*} 3$ has been debated, but a previous study indicated that the $C Y P 2 A 6^{*} 3$ genetic variant was the result of multiple CYP2A6 and CYP2A7 gene conversions [59]. The $C Y P 2 A 6^{*} 4$ is from a deletion in the CYP2A6 gene. The CYP $2 A 6^{*} 1 \times 2$ comprises a variation at 2 sites in the $C Y P 2 A 6$ gene, and the $C Y P 2 A 6^{*} 1 B$ allele is caused by gene conversion in the $3^{\prime}$-untranslated region of CYP2A7.

The various alleles of $C Y P 2 A$ express at least 13 different isoenzymes, among which CYP2A6 metabolically activates the $N$-alkylnitrosamines, $N$-nitrosonornicotine, and 4(methylnitrosamino)-1-(3-pyridyl)-1-butanone, which have relatively long alkyl chains [62, 63]. Miyazaki et al. first reported that CYP2A subfamilies play important roles in the mutagenic activation of AN-derived $N$-nitrosamines [35]. The CYP2A6 P450 enzymes are the primary activators of MNPN. In Asia, the most common variant of CYP2A6 is $C Y P 2 A 6^{*} 4$ (the CYP2A6 deletion). The frequency of CYP2A6 ${ }^{*} 4$ is approximately $6.6 \%$ to $15.1 \%$ in the Chinese population. It is the most common genetic variant in the Japanese population, occurring at a frequency of $20.0 \%$ to $31.0 \%$ (Table 2).

People are classified as poor (PM), extensive (EM), or ultrarapid metabolizers (UM) based on their type of genetic variation [64]. The UMs have 2 active alleles of the CYP2A6 gene, including the CYP2A6 ${ }^{*} 1 \times 2$ variant. Phenotyping assays have indicated that 2 or more copies of active CYP2A6 alleles may result in a rapider nicotine metabolism. People with 1 or 2 copies of active gene alleles, such as CYP2A $6^{*} 1 /^{*} 1$, are extensive metabolizers $[60,65]$, whereas PMs are those with null alleles, such as $C Y P 2 A 6^{*} 2 /^{*} 2$ or $C Y P 2 A 6^{*} 4 /^{*} 4$, with no enzyme function or less activity regarding probe substrates. People who are homozygous for the CYP2A $6^{*} 2$ allele have little coumarin-hydroxylation activity $(<0.1 \%)[60,61]$, and EMs exhibit low activity $(<15 \%)$ when nicotine is used as the probe substrate $[58,60,66,67]$.

Previous reports have indicated that the deletion of CYP2A6 $\left(C Y P 2 A 6^{*} 4 C\right)$ may reduce the risk of lung cancer [68-71], suggesting that people with $C Y P 2 A 6^{*} 4 C$ may not activate tobacco nitrosamines from smoking. Because a genetic variation within the CYP2A6 gene appears to reduce 
TABLE 1: Detected saliva levels (ng/mL) of nitrosamines such as MNPN, NGL, and NGC in chewers with tobacco and without tobacco.

\begin{tabular}{lccc}
\hline BQ-specific $N$-nitrosamines & BQ alone (without tobacco) & BQ + tobacco & References \\
\hline MNPN & $0.5-11.4$ & $-{ }^{\mathrm{a}}$ & Prokopczyk et al., 1987 [36] \\
& $0-5.9$ & $0-7.1$ & Nair et al., 1985 [38] \\
NGL & $0.6-8.8$ & $3.1-23.5$ & Nair et al., 1987 [39] \\
& $2.2-9.5^{\mathrm{b}}$ & $4.3-45^{\mathrm{b}}$ & Wenke et al., 1984 [40] \\
NGC & $0-142$ & - & Stich, 1986 [41] \\
\hline
\end{tabular}

Adapted from [16].

BQ: betel quid.

${ }^{\mathrm{a}}$ The data not reported.

${ }^{\mathrm{b}}$ In $\mathrm{ppb}$.

xenobiotic activation, CYP2A6 polymorphisms may also reduce the metabolic activation of $\mathrm{AN}$-derived nitrosamines. In Sri Lanka, a study found that the deletion polymorphism, CYP $2 A 6^{*} 4 C /^{*} 4 C$, reduces susceptibility to oral squamous cell carcinoma $(\mathrm{OR}=0.14 ; 95 \% \mathrm{CI}, 0.03-0.72)$ among habitual BQ chewers with oral lesions, suggesting that BQ chewers with reduced CYP2A6 activity because of polymorphisms may be at lower risk for oral cancer [30].

2.5. The N-Nitrosamine-Metabolizing CYP2E Gene. The CYP2E subfamilies include CYP2E1 and CYP2E2. The CYP2E1 gene has been shown to be the primary activator of $N$-nitrosodimethylamine and $N$-nitrosodiethylamine, which are $N$-nitrosamines with relatively short alkyl chains $[62,63]$. A case-control study of 41 male oral cancer patients and 123 healthy controls found that people with the CYP2E1 $\mathrm{c} 1 / \mathrm{c} 2$ or $\mathrm{c} 2 / \mathrm{c} 2$ genotype had a higher risk of oral cancer (multicovariate-adjusted $\mathrm{OR}=2.0 ; 95 \% \mathrm{CI}, 0.8-5.4$ ) than those with the $\mathrm{cl} / \mathrm{cl}$ genotype [27]. However, the association was not statistically significant. Hung et al. also reported a significant association between CYP2E1 polymorphisms and oral cancer among those without BQ-chewing habits $(\mathrm{OR}=$ 4.7; 95\% CI, 1.1-20.2), but not among BQ chewers [27]. All BQ chewers were also cigarette smokers, and the chewing habits had a significant effect on the risk of oral cancer. Thus, Hung et al. suggested that the risk of oral cancer associated with combined habits of BQ chewing and smoking may be too striking to have modified effects by the CYP2E1 genotype. A more recent study showed that polymorphisms in CYP2E1 within the PstI site (+/-) were significantly associated with oral submucous fibrosis ( $\mathrm{OR}=3.14 ; 95 \% \mathrm{CI}, 1.14-8.62)$ [51].

2.6. Arecoline-Induced, CYP26B1-Mediated Retinoic Acid Metabolism. In a previous study, we treated normal human gingival fibroblasts (HGFs) with arecoline and screened for the presence of a novel CYP26B1 by using a microarray [72]. The expression of CYP26B1 was subsequently confirmed using quantitative reverse transcription and real-time polymerase chain reaction [48]. The CYP26B1 gene is located at the human 2p13.2 region and may play an important role in variations in retinoic acid (RA) metabolism associated with oral lesions. Hyperkeratosis and hyperplasia of the oral mucosa can be caused by insufficient retinol intake [73], and the findings of previous studies have indicated that remission of oral leukoplakia in BQ chewers treated with RA may result from the suppression of $\mathrm{AN}$-related metabolism, rather than the inhibition of tumorigenesis [74-76]. Because it is a critical regulator of cell proliferation, cell differentiation, and apoptosis, RA deficiency may play an important role in carcinogenesis [73, 77-79].

At an RA concentration of $100 \mu \mathrm{g} / \mathrm{mL}$, the repression level of CYP26B1 was approximately 15-fold in cultured primary HGFs obtained from a healthy volunteer in our previous study [72]. We suggested that CYP26B1 may be involved in detoxification processes, and arecoline treatment in normal HGFs was shown to repress susceptibility [72]. We detected higher levels of CYP26B1 mRNA and protein expression in human oral cancer cells compared with adjacent noncancerous tissues. The findings of another previous study suggested that CYP26B1 mRNA is predominantly expressed in the adult human cerebellum and may be associated with the protection of specific human tissues from exposure to RA [80]. We found that the CYP26B1 polymorphism AA significantly correlated with the risk of oral cancer $(\mathrm{OR}=2.26$; 95\% CI, 1.35-3.80), and BQ chewers with the AA genotype had a significantly increased risk of oral cancer $(\mathrm{OR}=70.04$; 95\% CI, 13.62360.11). We concluded that CYP26B1 is a novel candidate gene in the development of BQ-related oral cancer and speculated that CYP26B1 may be involved in the metabolism of arecoline-related compounds [48].

In the oral mucosa of BQ chewers, CYP26B1 induction alters the RA metabolism [79]. A previous study demonstrated that CYP26 members may play a role in RA accumulation in human epidermal keratinocytes [81]. Klaassen et al. [82] found higher levels of RA-inducible CYP26 mRNA expression and higher RA turnover rates in oral squamous cell carcinoma cell lines, compared with noncancerous oral $\mathrm{KB}$ cells, and that oral $\mathrm{KB}$ cells from cancer patients exhibit a 15 -fold higher RA turnover rate compared with noncancerous oral $\mathrm{KB}$ cells [83].

A previous study indicated that high-level CYP26 expression may be associated with head and neck cancer [82]. The expression of CYP26 was induced through an RA-receptormediated mechanism in breast and colon carcinoma cells [84]. A higher expression of CYP26 caused intracellular RA depletion in Barrett-associated adenocarcinoma [78], whereas other studies have indicated that the expression of CYP26 is downregulated in noncancerous human epidermis 


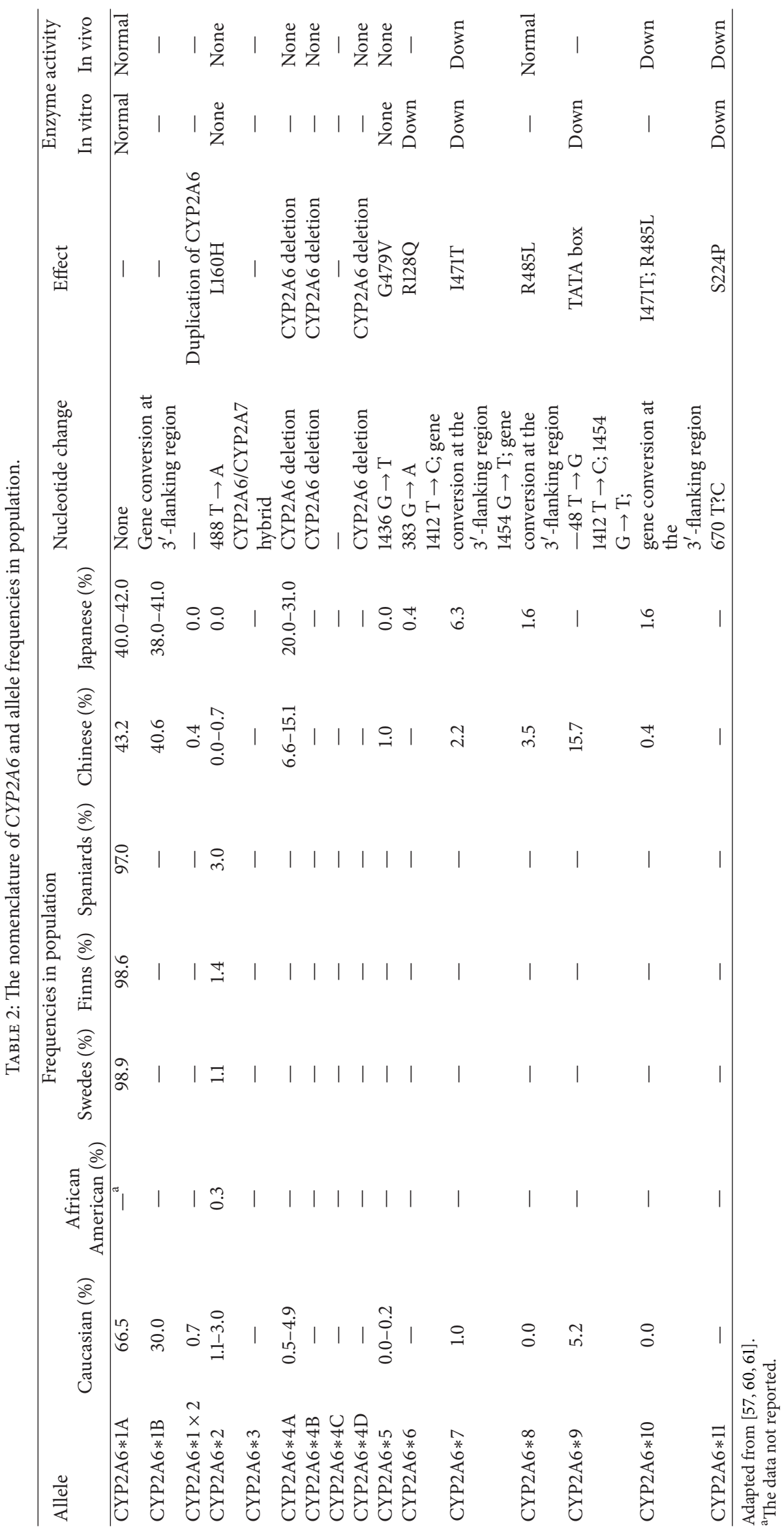




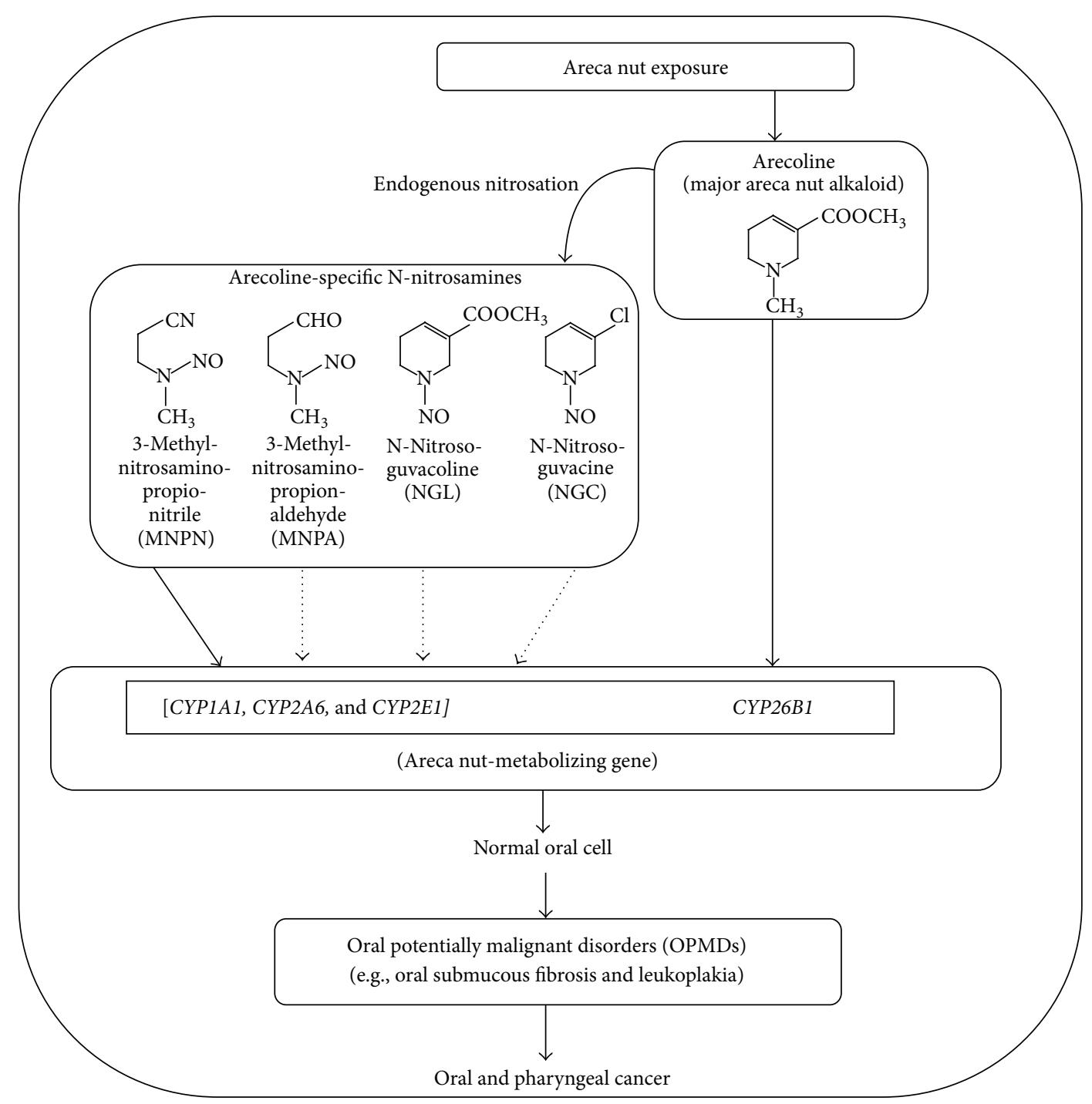

FIGURE 1: Simplified flow chart for postulated main effects of areca nut induced oral carcinogenesis via cytochrome P450 (CYP) gene.

$[85,86]$. These findings indicate that the RA metabolism is an important factor in the development of oral cancer.

\section{Discussion}

Oral cancer is one of the most common cancers worldwide and was ranked the eighth leading cause of cancer-related deaths in 2000 [1]. Incidence rates of 8.8 and 5.1 per 100000 cases and mortality rates of 7.3 and 3.2 per 100000 cases have been reported for oral cancer among males and females, respectively [1]. In Taiwan, BQ production has increased approximately 44-fold [16]. An international study found that Taiwan had the fourth highest prevalence of oral and pharyngeal cancers, preceded by Papua New Guinea, the Solomon Islands, and Sri Lanka [2]. In BQ-endemic areas, oral and pharyngeal cancers and the most common OPMDs (such as OSF and oral leukoplakia) appear to be associated with BQ use, whereas cigarette smoking and heavy alcohol drinking are the major risk factors in western countries.
Numerous genes are involved in carcinogen metabolism, and most studies have found that CYP polymorphisms affect the risk of oral cancer associated with variations in the metabolism of tobacco-derived carcinogens. Arecoline, arecaidine, and other BQ-related metabolites may exist at nanogram concentrations in human blood, and the level of arecoline is significantly associated with the quantity of BQ used [87]. We summarized the findings of studies of the effects of CYP polymorphisms on BQ chewing-related symptoms, including cancer of the oral cavity and pharynx and OPMDs, in Table 3. Among xenobiotic metabolizing enzymes, CYP1A1, CYP2A6, and CYP2E1 may activate ANderived nitrosamines. In addition, the expression of CYP26B1 may be induced by arecoline and may be related to RA metabolism. The flowchart in Figure 1 depicts the main effects of CYP genetic variants on $\mathrm{AN}$-induced carcinogenesis.

To the best of our knowledge, only 2 studies have reported a relationship between the genetic polymorphism of CYP1A1 and the risk of oral cancer and OPMDs [29, 51]. 
TABLE 3: The association studies between cytochrome P450 (CYP) polymorphism and betel quid-related oral disorders.

\begin{tabular}{|c|c|c|c|c|c|}
\hline $\begin{array}{l}\text { CYP } \\
\text { gene }\end{array}$ & $\begin{array}{l}\text { Cases/number } \\
\text { Controls/ number }\end{array}$ & $\begin{array}{l}\text { Chewing habit } \\
\text { of cases/controls }\end{array}$ & OR (95\% CI) & Conclusion & $\begin{array}{l}\text { Population/ } \\
\text { reference }\end{array}$ \\
\hline \multirow[t]{4}{*}{ CYP1A1 } & $\begin{array}{l}\text { Oral cancer/106 } \\
\text { Controls/146 }\end{array}$ & $\begin{array}{l}\text { BQ, } \\
62.3 \% / 15.0 \%\end{array}$ & $\begin{array}{l}\text { Gene effects: Exon } 7 \text { A/G (ile/val) } \\
\text { A/G versus A/A, } 5.08(2.64-9.76)^{*} \\
\text { G/G versus A/A, } 18.86(3.61-98.52)^{*}\end{array}$ & $\begin{array}{l}\text { Subjects with CYP1A1 } \\
\text { carrying G allele } \\
\text { increased the risk for } \\
\text { OPMDs and oral } \\
\text { cancer }\end{array}$ & Taiwan/[29] \\
\hline & $\begin{array}{l}\text { OPMDs } / 60 \\
\text { Controls } / 146\end{array}$ & $\begin{array}{l}\text { BQ, } \\
75.0 \% / 15.0 \%\end{array}$ & $\begin{array}{l}\text { Gene effects: Exon } 7 \text { A/G (ile/val) } \\
\text { A/G versus A/A, } 2.67(1.32-5.40)^{*} \\
\text { G/G versus A/A, } 15.23(2.76-83.98)^{*}\end{array}$ & & \\
\hline & & & Gene effects: $3^{\prime}$ UTR $M s p$ I site & $\begin{array}{l}\text { No significant } \\
\text { association }\end{array}$ & \\
\hline & $\begin{array}{l}\text { OSF } / 75 \\
\text { Controls } / 150\end{array}$ & & $\begin{array}{l}\text { Gene effects: } \mathrm{m} 1 \text { at } M \text { spI site } \\
\quad(+/-) \text { versus }(+/+), 2.88(1.57-5.24)^{*} \\
\quad(-/-) \text { versus }(+/+), 3.16(1.10-9.04)^{*} \\
\text { Gene effects: } \mathrm{m} 2 \text { at } N \text { coI site } \\
\quad(-/-) \text { versus }(+/+), 8.25(4.31-15.80)^{*}\end{array}$ & $\begin{array}{l}\text { Subjects with CYP1A1 } \\
\text { polymorphisms had } \\
\text { significantly increased } \\
\text { risks of OSF }\end{array}$ & India/[51] \\
\hline CYP2A6 & $\begin{array}{l}\text { Oral lesions/286 } \\
\text { (15 oral cancer, } 62 \\
\text { OSF and } 209 \\
\text { leukoplakia) } \\
\text { Controls/135 }\end{array}$ & $\begin{array}{l}\text { betel, } \\
100 \% / 100 \%\end{array}$ & $\begin{array}{l}\text { Gene effects } \\
\quad{ }^{*} 1 B /{ }^{*} 4 C \text { versus }{ }^{*} 1 A /^{*} 1 A, 0.21(0.05-0.88)^{*} \\
\quad{ }^{*} 4 C /^{*} 4 C \text { versus }{ }^{*} 1 A /^{*} 1 A, 0.14(0.03-0.72)^{*}\end{array}$ & $\begin{array}{l}\text { BQ chewers with } \\
\text { activity deficient of } \\
C Y P 2 A 6 \text { deletion } \\
\text { decreased the risk of } \\
\text { oral cancer }\end{array}$ & Sri Lanka/[30] \\
\hline \multirow{3}{*}{ CYP2E1 } & & & $\begin{array}{l}\text { Gene effects } \\
\mathrm{cl} / \mathrm{c} 2+\mathrm{c} 2 / \mathrm{c} 2 \text { versus } \mathrm{cl} / \mathrm{cl}, 2.0(0.8-5.4)\end{array}$ & $\begin{array}{l}\text { A significant } \\
\text { relationship between } \\
C Y P 2 E 1\end{array}$ & \\
\hline & $\begin{array}{l}\text { Oral cancer/41 } \\
\text { Controls/123 }\end{array}$ & $\begin{array}{l}\text { BQ, } \\
73.2 \% / 12.2 \%\end{array}$ & $\begin{array}{l}\text { Among nonchewers } \\
\mathrm{cl} / \mathrm{c} 2+\mathrm{c} 2 / \mathrm{c} 2 \text { versus } \mathrm{cl} / \mathrm{cl}, 4.7(1.1-20.2)^{*} \\
\text { Among chewers } \\
\mathrm{cl} / \mathrm{c} 2+\mathrm{c} 2 / \mathrm{c} 2 \text { versus } \mathrm{cl} / \mathrm{cl}, 0.8(0.2-3.3)\end{array}$ & $\begin{array}{l}\text { polymorphisms and } \\
\text { oral cancer risk was } \\
\text { found among non-BQ } \\
\text { chewers }\end{array}$ & Taiwan/[27] \\
\hline & $\begin{array}{l}\text { Oral cancer } / 106 \\
\text { Controls } / 146\end{array}$ & & $\begin{array}{l}\text { Gene effects: at } P s t \mathrm{I} \text { site } \\
\qquad(+/-) \text { versus }(+/+), 3.14(1.14-8.62)^{*}\end{array}$ & $\begin{array}{l}\text { Individuals with } \\
C Y P 2 E 1 \text { at } P s t \text { I site } \\
\text { polymorphism }(+/-) \\
\text { may confer a } \\
\text { significantly increased } \\
\text { risk for oral cancer }\end{array}$ & India/[51] \\
\hline \multirow[t]{2}{*}{ CYP26B1 } & $\begin{array}{l}\text { Oral cancer } / 247 \\
\text { Controls } / 338\end{array}$ & $\begin{array}{l}\text { BQ, } \\
85.4 \% / 22.5 \%\end{array}$ & $\begin{array}{l}\text { rs707718 } \\
\text { Gene effects } \\
\text { A versus C, } 1.48(1.16-1.87)^{*} \\
\text { AA versus CC, } 2.26(1.35-3.80)^{*} \\
\text { Gene-BQ }(+/-) \text { interplay } \\
\text { AA-BQ (+) versus CC-BQ }(-), 70.04 \\
(13.62-360.11)^{*}\end{array}$ & $\begin{array}{l}\text { BQ chewing } \\
\text { interacted with } \\
\text { CYP26B1-AA } \\
\text { significantly increased } \\
\text { the risk of oral cancer }\end{array}$ & \multirow[t]{2}{*}{ Taiwan/[48] } \\
\hline & & & $\begin{array}{l}\text { Gene effects } \\
\quad \text { rs } 2241057, \text { rs } 2286965, \text { rs } 3768641\end{array}$ & $\begin{array}{l}\text { No significant } \\
\text { findings }\end{array}$ & \\
\hline
\end{tabular}

OPMDs: oral potentially malignant disorders; OSF: oral submucous fibrosis; betel: betel quid chewing with or without tobacco; BQ: betel quid without tobacco; OR: odds ratios; CI: confidence interval; ${ }^{*}$ statistical significance.

Higher-risk patients with the CYP1A1 G (val) allele should be strongly encouraged to avoid BQ use and maintain good oral hygiene. People with the $C Y P 2 A 6^{*} 4 C /^{*} 4 C$ genetic variant may be at lower risk of oral cancer because their genotype suppresses the activation of AN-related procarcinogens [30]. The CYP2E1 polymorphisms may increase the risk of oral cancer $[27,51]$. In addition, the findings of our previous study suggest that the combination of higher CYP26B1 expression and polymorphism is associated with an increased risk of oral cancer [48].
Future studies on CYP26B1 antagonists may identify novel RA-related methods of chemoprevention or treatment for OPMDs. Patients with high-risk alleles who chew BQ have an elevated risk for oral and pharyngeal cancers, and the risk is particularly high for OPMDs patients. We propose that the high-risk genotypes, such as CYP1A1, CYP2A6, CYP2E1, and CYP26B1, should be targeted for the development of a single-nucleotide polymorphism (SNP) gene chip for risk assessment in OPMDs patients, especially for those with BQ chewing habits. 


\section{Conclusion}

The accumulation of such findings will be useful for the identification of high-risk patients and the development of novel therapeutic strategies for blocking the activation of AN-related compounds and targeting the CYP gene. Largescale studies on the polymorphisms of CYP genes in BQ chewers and the genetic variants related to oral and pharyngeal cancers or OPMDs are warranted. The identification of molecular mechanisms elucidated by future pharmacogenomics studies will establish a strong foundation for the development of chemoprevention strategies, SNP-based clinical diagnostic tools (e.g., specific SNP barcodes for BQassociated oral disorders), and effective treatments for BQrelated oral disorders.

\section{Abbreviations}

OPMDs: Oral potentially malignant disorders

BQ: $\quad$ Betel quid

AN: $\quad$ Areca nut

NGL: $\quad N$-Nitrosoguvacoline

MNPA: 3-Methylnitrosaminopropionaldehyde

MNPN: 3-(Methylnitrosamino)propionitrile

NGC: $\quad N$-Nitrosoguvacine

RA: $\quad$ Retinoid acid.

\section{Conflict of Interests}

The authors declare no conflict of interests.

\section{Authors' Contribution}

Jen-Yang Tang and Ping-Ho Chen made equal contributions to this work.

\section{Acknowledgments}

This study was supported by Grants from the Chi-Mei Medical Center and Kaohsiung Medical University Research Foundation (100CM-KMU-13 and 101CM-KMU-12), a Grant from the Department of Health, Executive Yuan, Taiwan (DOH102-TD-C-111-002), and a Grant from National Science Council (NSC Grants 100-2113-M-037-012-MY2). The authors thank Dr. Ker-Kong Chen (School of Dentistry, College of Dental Medicine, Kaohsiung Medical University, Kaohsiung, Taiwan; Division of Conservative Dentistry, Department of Dentistry, Kaohsiung Medical University Hospital, Kaohsiung, Taiwan) for providing insightful comments on this paper.

\section{References}

[1] K. Shibuya, C. D. Mathers, C. Boschi-Pinto, A. D. Lopez, and C. J. L. Murray, "Global and regional estimates of cancer mortality and incidence by site: II. Results for the global burden of disease 2000," BMC Cancer, vol. 2, article 37, 2002.

[2] S. Tovosia, P. Chen, A. M. Ko, H. Tu, P. Tsai, and Y. Ko, "Prevalence and associated factors of betel quid use in the Solomon Islands: a hyperendemic area for oral and pharyngeal cancer,"
American Journal of Tropical Medicine and Hygiene, vol. 77, no. 3, pp. 586-590, 2007.

[3] Bureau of Health Promotion, Department of Health, Cancer Registration System Annual Report, Bureau of Health Promotion, Department of Health, New Taipei City, Taiwan, 2010.

[4] S. Warnakulasuriya, N. W. Johnson, and I. van der Waal, "Nomenclature and classification of potentially malignant disorders of the oral mucosa," Journal of Oral Pathology and Medicine, vol. 36, no. 10 , pp. 575-580, 2007.

[5] H. K. Amarasinghe, U. S. Usgodaarachchi, N. W. Johnson, R. Lalloo, and S. Warnakulasuriya, "Betel-quid chewing with or without tobacco is a major risk factor for oral potentially malignant disorders in Sri Lanka: a case-control study," Oral Oncology, vol. 46, no. 4, pp. 297-301, 2010.

[6] Y. C. Ko, Y. L. Huang, C. H. Lee et al., "Betel quid chewing, cigarette smoking and alcohol consumption related to oral cancer in Taiwan," Journal of Oral Pathology and Medicine, vol. 24, no. 10, pp. 450-453, 1995.

[7] C.-H. Lee, Y.-C. Ko, H.-L. Huang et al., "The precancer risk of betel quid chewing, tobacco use and alcohol consumption in oral leukoplakia and oral submucous fibrosis in southern Taiwan," British Journal of Cancer, vol. 88, no. 3, pp. 366-372, 2003.

[8] C. Lu, Y. Yen, C. Ho et al., "A case-control study of oral cancer in Changhua County, Taiwan," Journal of Oral Pathology and Medicine, vol. 25, no. 5, pp. 245-248, 1996.

[9] Y. Yang, H. Lee, S. Tung, and T. Shieh, "Epidemiological survey of oral submucous fibrosis and leukoplakia in aborigines of Taiwan," Journal of Oral Pathology and Medicine, vol. 30, no. 4, pp. 213-219, 2001.

[10] P. C. Gupta and C. S. Ray, "Epidemiology of betel quid usage," Annals of the Academy of Medicine Singapore, vol. 33, supplement 4, pp. 31-36, 2004.

[11] J. Changrani and F. Gany, "Paan and gutka in the United States: an emerging threat," Journal of Immigrant Health, vol. 7, no. 2, pp. 103-108, 2005.

[12] P. C. Gupta and S. Warnakulasuriya, "Global epidemiology of areca nut usage," Addiction Biology, vol. 7, no. 1, pp. 77-83, 2002.

[13] Y.-C. Ko, T.-A. Chiang, S.-J. Chang, and S.-F. Hsieh, "Prevalence of betel quid chewing habit in Taiwan and related sociodemographic factors," Journal of Oral Pathology and Medicine, vol. 21, no. 6, pp. 261-264, 1992.

[14] P. Chen, Y. Ko, Y. Yang et al., "Important prognostic factors of long-term oropharyngeal carcinoma survivors in Taiwan," Oral Oncology, vol. 40, no. 8, pp. 847-855, 2004.

[15] P. Chen, T. Shieh, P. Ho et al., "Prognostic factors associated with the survival of oral and pharyngeal carcinoma in Taiwan," BMC Cancer, vol. 7, article 101, 2007.

[16] IARC, IARC Betel-Quid and Areca-Nut Chewing and Some Areca-Nut-Derived Nitrosamines, Volume 85: IARC Monographs on the Evaluation of Carcinogenic Risks to Humans, IARC, Fairbanks, Alaska, USA, 2004.

[17] N.-S. Chu, "Effects of Betel chewing on the central and autonomic nervous systems," Journal of Biomedical Science, vol. 8, no. 3, pp. 229-236, 2001.

[18] B. J. Dave, A. H. Trivedi, and S. G. Adhvaryu, "In vitro genotoxic effects of areca nut extract and arecoline," Journal of Cancer Research and Clinical Oncology, vol. 118, no. 4, pp. 283-288, 1992.

[19] S. Deb and A. Chatterjee, "Influence of buthionine sulfoximine and reduced glutathione on arecoline-induced chromosomal damage and sister chromatid exchange in mouse bone marrow cells in vivo," Mutagenesis, vol. 13, no. 3, pp. 243-248, 1998. 
[20] L. P. Shirname, M. M. Menon, and S. V. Bhide, "Mutagenicity of betel quid and its ingredients using mammalian test systems," Carcinogenesis, vol. 5, no. 4, pp. 501-503, 1984.

[21] J. H. Jeng, M. C. Chang, and L. J. Hahn, "Role of areca nut in betel quid-associated chemical carcinogenesis: current awareness and future perspectives," Oral Oncology, vol. 37, no. 6, pp. 477-492, 2001.

[22] H. Bartsch, U. Nair, A. Risch, M. Rojas, H. Wikman, and K. Alexandrov, "Genetic polymorphism of CYP genes, alone or in combination, as a risk modifier of tobacco-related cancers," Cancer Epidemiology Biomarkers and Prevention, vol. 9, no. 1, pp. 3-28, 2000.

[23] T. Ho, Q. Wei, and E. M. Sturgis, "Epidemiology of carcinogen metabolism genes and risk of squamous cell carcinoma of the head and neck," Head and Neck, vol. 29, no. 7, pp. 682-699, 2007.

[24] T. A. Patterson and J. W. Kosh, "Elucidation of the rapid in vivo metabolism of arecoline," General Pharmacology, vol. 24, no. 3, pp. 641-647, 1993.

[25] P. Pavek and Z. Dvorak, "Xenobiotic-induced transcriptional regulation of xenobiotic metabolizing enzymes of the cytochrome P450 superfamily in human extrahepatic tissues," Current Drug Metabolism, vol. 9, no. 2, pp. 129-143, 2008.

[26] S. Giri, J. R. Idle, C. Chen, T. M. Zabriskie, K. W. Krausz, and F. J. Gonzalez, "A metabolomic approach to the metabolism of the areca nut alkaloids arecoline and arecaidine in the mouse," Chemical Research in Toxicology, vol. 19, no. 6, pp. 818-827, 2006.

[27] H. Hung, J. Chuang, Y. Chien et al., "Genetic polymorphisms of CYP2E1, GSTM1, and GSTT1; environmental factors and risk of oral cancer," Cancer Epidemiology Biomarkers and Prevention, vol. 6, no. 11, pp. 901-905, 1997.

[28] S. Kietthubthew, H. Sriplung, and W. W. Au, "Genetic and environmental interactions on oral cancer in Southern Thailand," Environmental and Molecular Mutagenesis, vol. 37, no. 2, pp. 111116, 2001.

[29] S. Kao, C. Wu, S. Lin et al., "Genetic polymorphism of cytochrome P4501Al and susceptibility to oral squamous cell carcinoma and oral precancer lesions associated with smoking/betel use," Journal of Oral Pathology and Medicine, vol. 31, no. 9, pp. 505-511, 2002.

[30] Z. Topcu, I. Chiba, M. Fujieda et al., "CYP2A6 gene deletion reduces oral cancer risk in betel quid chewers in Sri Lanka," Carcinogenesis, vol. 23, no. 4, pp. 595-598, 2002.

[31] M. Hernando-Rodriguez, N. Rey-Barja, X. Marichalar-Mendia, M. J. Rodriguez-Tojo, A. Acha-Sagredo, and J. M. AguirreUrizar, "Role of cytochrome P-450 genetic polymorphisms in oral carcinogenesis," Journal of Oral Pathology and Medicine, vol. 41, no. 1, pp. 1-8, 2012.

[32] K. Tanimoto, S. Hayashi, K. Yoshiga, and T. Ichikawa, "Polymorphisms of the CYP1A1 and GSTM1 gene involved in oral squamous cell carcinoma in association with a cigarette dose," Oral Oncology, vol. 35, no. 2, pp. 191-196, 1999.

[33] T. Katoh, S. Kaneko, K. Kohshi et al., "Genetic polymorphisms of tobacco- and alcohol-related metabolizing enzymes and oral cavity cancer," International Journal of Cancer, vol. 83, no. 5, pp. 606-609, 1999.

[34] G. Wenke and D. Hoffmann, "A study of betel quid carcinogenesis. I. On the in vitro N-nitrosation of arecoline," Carcinogenesis, vol. 4, no. 2, pp. 169-172, 1983.

[35] M. Miyazaki, E. Sugawara, T. Yoshimura, H. Yamazaki, and T. Kamataki, "Mutagenic activation of betel quid-specific $\mathrm{N}$-nitrosamines catalyzed by human cytochrome P450 coexpressed with NADPH-cytochrome P450 reductase in Salmonella typhimurium YG7108," Mutation Research, vol. 581, no. 1-2, pp. 165-171, 2005.

[36] B. Prokopczyk, A. Rivenson, and P. Bertinato, "3-(methylnitrosamino)propionitrile: occurrence in saliva of betel quid chewers, carcinogenicity, and DNA methylation in F344 rats," Cancer Research, vol. 47, no. 2, pp. 467-471, 1987.

[37] D. Hoffmann, K. D. Brunnemann, B. Prokopczyk, and M. V. Djordjevic, "Tobacco-specific N-nitrosamines and Arecaderived N-nitrosamines: chemistry, biochemistry, carcinogenicity, and relevance to humans," Journal of Toxicology and Environmental Health, vol. 41, no. 1, pp. 1-52, 1994.

[38] J. Nair, H. Ohshima, and M. Friesen, "Tobacco-specific and betel nut-specific N-nitroso compounds: occurrence in saliva and urine of betel quid chewers and formation in vitro by nitrosation of betel quid," Carcinogenesis, vol. 6, no. 2, pp. 295-303, 1985.

[39] J. Nair, U. J. Nair, H. Ohshima, S. V. Bhide, and H. Bartsch, "Endogenous nitrosation in the oral cavity of chewers while chewing betel quid with or without tobacco," IARC Scientific Publications, vol. 84, pp. 465-469, 1987.

[40] G. Wenke, K. D. Brunnemann, D. Hoffmann, and S. V. Bhide, "A study of betel quid carcinogenesis. IV. Analysis of the saliva of Betel chewers: a preliminary report," Journal of Cancer Research and Clinical Oncology, vol. 108, no. 1, pp. 110-113, 1984.

[41] H. F. Stich, "Reducing the genotoxic damage in the oral mucosa of betel quid/tobacco chewers," Basic Life Sciences, vol. 39, pp. 381-391, 1986.

[42] J. Nair, H. Ohshima, B. Pignatelli et al., "Modifiers of endogenous carcinogen formation: studies on in vivo nitrosation in tobacco users," in Mechanisms in Tobacco Carcinogenisis (Banbury Report 23), D. Hoffman and C. C. Harris, Eds., pp. 45-61, CSH Press, Cold Spring Harbor, NY, USA, 1986.

[43] P. P. Chakradeo, J. Nair, and S. V. Bhide, "Endogenous formation of $\mathrm{N}$-nitrosoproline and other $\mathrm{N}$-nitrosamino acids in tobacco users," Cancer Letters, vol. 86, no. 2, pp. 187-194, 1994.

[44] H. Ernst, H. Ohshima, H. Bartsch, U. Mohr, and P. Reichart, "Tumorigenicity study in Syrian hamsters fed areca nut together with nitrite," Carcinogenesis, vol. 8, no. 12, pp. 1843-1845, 1987.

[45] H. Ohshima, M. Friesen, and H. Bartsch, "Identification in rats of $\mathrm{N}$-nitrosonipecotic acid as a major urinary metabolite of the areca-nut alkaloid-derived nitrosamines, $\mathrm{N}$-nitrosoguvacoline and N-nitrosoguvacine," Cancer Letters, vol. 44, no. 3, pp. 211$216,1989$.

[46] U. Nair, H. Bartsch, and J. Nair, "Alert for an epidemic of oral cancer due to use of the betel quid substitutes gutkha and pan masala: a review of agents and causative mechanisms," Mutagenesis, vol. 19, no. 4, pp. 251-262, 2004.

[47] K. Lee, W. Kuo, S. Tsai et al., "Different impact from betel quid, alcohol and cigarette: risk factors for pharyngeal and laryngeal cancer," International Journal of Cancer, vol. 117, no. 5, pp. 831836, 2005.

[48] P. Chen, K. Lee, C. Chen et al., "CYP26B1 is a novel candidate gene for betel quid-related oral squamous cell carcinoma," Oral Oncology, vol. 47, no. 7, pp. 594-600, 2011.

[49] I. Cha, J. Y. Park, W. Chung, M. Choi, H. Kim, and K. Park, "Polymorphisms of CYP1A1 and GSTM1 genes and susceptibility to oral cancer," Yonsei Medical Journal, vol. 48, no. 2, pp. 233-239, 2007.

[50] J. Y. Park, J. E. Muscat, Q. Ren et al., "CYP1A1 and GSTM1 polymorphisms and oral cancer risk," Cancer Epidemiology Biomarkers and Prevention, vol. 6, no. 10, pp. 791-797, 1997. 
[51] S. R. Chaudhuri, S. Mukherjee, R. R. Paul, A. Haldar, and K. Chaudhuri, "CYP1AI and CYP2E1 gene polymorphisms may increase susceptibility to Oral Submucous Fibrosis among betel quid chewers of Eastern India," Gene, vol. 513, no. 2, pp. 268-271, 2013.

[52] H. Yamazaki, Y. Inui, C.-H. Yun, F. P. Guengerich, and T. Shimada, "Cytochrome P450 2E1 and 2A6 enzymes as major catalysts for metabolic activation of $\mathrm{N}$-nitrosodialkylamines and tobacco-related nitrosamines in human liver microsomes," Carcinogenesis, vol. 13, no. 10, pp. 1789-1794, 1992.

[53] C. J. Patten, T. J. Smith, M. J. Friesen, R. E. Tynes, C. S. Yang, and S. E. Murphy, "Evidence for cytochrome P450 2A6 and 3A4 as major catalysts for $\mathrm{N}^{\prime}$-nitrosonornicotine $\alpha$-hydroxylation by human liver microsomes," Carcinogenesis, vol. 18, no. 8, pp. 1623-1630, 1997.

[54] T. Nakagawa, M. Sawada, F. J. Gonzalez, T. Yokoi, and T. Kamataki, "Stable expression of human CYP2E1 in Chinese hamster cells: high sensitivity to N,N-dimethylnitrosamine in cytotoxicity testing," Mutation Research, vol. 360, no. 3, pp. 181186, 1996.

[55] P. Fernandez-Salguero and F. J. Gonzalez, "The CYP2A gene subfamily: species differences, regulation, catalytic activities and role in chemical carcinogenesis," Pharmacogenetics, vol. 5, pp. S123-S128, 1995.

[56] S. M. G. Hoffman, P. Fernandez-Salguero, F. J. Gonzalez, and H. W. Mohrenweiser, "Organization and evolution of the cytochrome P450 CYP2A-2B-2F subfamily gene cluster on human chromosome 19," Journal of Molecular Evolution, vol. 41, no. 6, pp. 894-900, 1995.

[57] A. R. Tricker, "Nicotine metabolism, human drug metabolism polymorphisms, and smoking behaviour," Toxicology, vol. 183, no. 1-3, pp. 151-173, 2003.

[58] M. Nakajima, J. Kwon, N. Tanaka et al., "Relationship between interindividual differences in nicotine metabolism and CYP2A6 genetic polymorphism in humans," Clinical Pharmacology and Therapeutics, vol. 69, no. 1, pp. 72-78, 2001.

[59] M. Oscarson, R. A. McLellan, H. Gullstén et al., "Identification and characterisation of novel polymorphisms in the CYP2A locus: Implications for nicotine metabolism," FEBS Letters, vol. 460, no. 2, pp. 321-327, 1999.

[60] C. Xu, S. Goodz, E. M. Sellers, and R. F. Tyndale, "CYP2A6 genetic variation and potential consequences," Advanced Drug Delivery Reviews, vol. 54, no. 10, pp. 1245-1256, 2002.

[61] M. Oscarson, H. Gullstén, A. Rautio et al., "Genotyping of human cytochrome P450 2A6 (CYP2A6), a nicotine C-oxidase," FEBS Letters, vol. 438, no. 3, pp. 201-205, 1998.

[62] H. Kushida, K. Fujita, A. Suzuki et al., "Metabolic activation of N-alkylnitrosamines in genetically engineered Salmonella typhimurium expressing CYP2E1 or CYP2A6 together with human NADPH-cytochrome P450 reductase," Carcinogenesis, vol. 21, no. 6, pp. 1227-1232, 2000.

[63] K. Fujita and T. Kamataki, "Role of human cytochrome P450 (CYP) in the metabolic activation of $\mathrm{N}$-alkylnitrosamines: application of genetically engineered Salmonella typhimurium YG7108 expressing each form of CYP together with human NADPH-cytochrome P450 reductase," Mutation Research, vol. 483, no. 1-2, pp. 35-41, 2001.

[64] M. Ingelman-Sundberg, "The Gerhard Zbinden Memorial Lecture. Genetic polymorphism of drug metabolizing enzymes. Implications for toxicity of drugs and other xenobiotics," Archives of Toxicology. Supplement, vol. 19, pp. 3-13, 1997.
[65] Y. Rao, E. Hoffmann, M. Zia et al., "Duplications and defects in the CYP2A6 gene: identification, genotyping, and in vivo effects on smoking," Molecular Pharmacology, vol. 58, no. 4, pp. 747$755,2000$.

[66] M. Nakajima, S. Yamagishi, H. Yamamoto, T. Yamamoto, Y. Kuroiwa, and T. Yokoi, "Deficient cotinine formation from nicotine is attributed to the whole deletion of the CYP2A6 gene in humans," Clinical Pharmacology and Therapeutics, vol. 67, no. 1, pp. 57-69, 2000.

[67] K. Kitagawa, N. Kunugita, T. Katoh, M. Yang, and T. Kawamoto, "The significance of the homozygous CYP2A6 deletion on nicotine metabolism: a new genotyping method of CYP2A6 using a single PCR-RFLP," Biochemical and Biophysical Research Communications, vol. 262, no. 1, pp. 146-151, 1999.

[68] T. Yokoi and T. Kamataki, "Genetic polymorphism of drug metabolizing enzymes: new mutations in CYP2D6 and CYP2A6 genes in Japanese," Pharmaceutical Research, vol. 15, no. 4, pp. 517-524, 1998.

[69] T. Kamataki, K. Nunoya, Y. Sakai, H. Kushida, and K. Fujita, "Genetic polymorphism of CYP2A6 in relation to cancer," Mutation Research, vol. 428, no. 1-2, pp. 125-130, 1999.

[70] K. Nunoya, T. Yokoi, K. Kimura et al., "A new CYP2A6 gene deletion responsible for the in vivo polymorphic metabolism of (+)-cis-3,5-dimethyl-2-(3-pyridyl)thiazolidin-4-one hydrochloride in humans," Journal of Pharmacology and Experimental Therapeutics, vol. 289, no. 1, pp. 437-442, 1999.

[71] M. Miyamoto, Y. Umetsu, H. Dosaka-Akita et al., "CYP2A6 gene deletion reduces susceptibility to lung cancer," Biochemical and Biophysical Research Communications, vol. 261, no. 3, pp. 658-660, 1999.

[72] S. Chiang, S. Jiang, Y. Wang et al., "Characterization of erecoline-induced effects on cytotoxicity in normal human gingival fibroblasts by global gene expression profiling," Toxicological Sciences, vol. 100, no. 1, pp. 66-74, 2007.

[73] S. Graham, "Epidemiology of retinoids and cancer," Journal of the National Cancer Institute, vol. 73, no. 6, pp. 1423-1428, 1984.

[74] H. F. Stich, A. P. Hornby, B. Mathew, R. Sankaranarayanan, and M. Krishnan Nair, "Response of oral leukoplakias to the administration of vitamin A," Cancer Letters, vol. 40, no. 1, pp. 93-101, 1988.

[75] H. F. Stich, M. P. Rosin, A. P. Hornby, B. Mathew, R. Sankaranarayanan, and M. K. Nair, "Remission of oral leukoplakias and micronuclei in tobacco/betel quid chewers treated with betacarotene and with beta-carotene plus vitamin A," International Journal of Cancer, vol. 42, no. 2, pp. 195-199, 1988.

[76] H. F. Stich and S. S. Tsang, "Promoting activity of betel quid ingredients and their inhibition by retinol," Cancer Letters, vol. 45, no. 1, pp. 71-77, 1989.

[77] J. S. Bertram, C. K. Chow, C. Cross, N. Krinsky, and L. Packer, "Inhibition of chemically induced neoplastic transformation by carotenoids: mechanistic studies," Annals of the New York Academy of Sciences, vol. 686, pp. 161-176, 1993.

[78] C.-L. Chang, E. Hong, P. Lao-Sirieix, and R. C. Fitzgerald, "A novel role for the retinoic acid-catabolizing enzyme CYP26A1 in Barrett's associated adenocarcinoma," Oncogene, vol. 27, no. 21, pp. 2951-2960, 2008.

[79] E. Sonneveld and P. T. van der Saag, "Metabolism of retinoic acid: Implications for development and cancer," International Journal for Vitamin and Nutrition Research, vol. 68, no. 6, pp. 404-410, 1998.

[80] J. A. White, H. Ramshaw, M. Taimi et al., "Identification of the human cytochrome P450, P450RAI-2, which is predominantly 
expressed in the adult cerebellum and is responsible for alltrans-retinoic acid metabolism," Proceedings of the National Academy of Sciences of the United States of America, vol. 97, no. 12, pp. 6403-6408, 2000.

[81] E. P. Loriè, H. Li, A. Vahlquist, and H. Törmä, “The involvement of cytochrome p 450 (CYP) 26 in the retinoic acid metabolism of human epidermal keratinocytes," Biochimica et Biophysica Acta, vol. 1791, no. 3, pp. 220-228, 2009.

[82] I. Klaassen, R. H. Brakenhoff, S. J. Smeets, G. B. Snow, and B. J. M. Braakhuis, "Enhanced turnover of all-trans-retinoic acid and increased formation of polar metabolites in head and neck squamous cell carcinoma lines compared with normal oral keratinocytes," Clinical Cancer Research, vol. 7, no. 4, pp. 10171025, 2001.

[83] I. Klaassen, J. Cloos, S. J. Smeets et al., "Nonmalignant oral keratinocytes from patients with head and neck squamous cell carcinoma show enhanced metabolism of retinoic acid," Oncology, vol. 63, no. 1, pp. 56-63, 2002.

[84] E. Sonneveld, C. E. van den Brink, B. M. van der Leede et al., "Human retinoic acid (RA) 4-hydroxylase (CYP26) is highly specific for all-trans-RA and can be induced through RA receptors in human breast and colon carcinoma cells," Cell Growth and Differentiation, vol. 9, no. 8, pp. 629-637, 1998.

[85] R. Heise, J. Mey, M. M. Neis et al., "Skin retinoid concentrations are modulated by CYP26AI expression restricted to basal keratinocytes in normal human skin and differentiated 3D skin models," Journal of Investigative Dermatology, vol. 126, no. 11, pp. 2473-2480, 2006.

[86] C. Popa, A. J. Dicker, A. L. Dahler, and N. A. Saunders, "Cytochrome P450, CYP26AI, is expressed at low levels in human epidermal keratinocytes and is not retinoic acid-inducible," British Journal of Dermatology, vol. 141, no. 3, pp. 460-468, 1999.

[87] I. Wu, P. Chen, C. Wang et al., "Quantification of blood betel quid alkaloids and urinary 8-hydroxydeoxyguanosine in humans and their association with betel chewing habits," Journal of Analytical Toxicology, vol. 34, no. 6, pp. 325-331, 2010. 

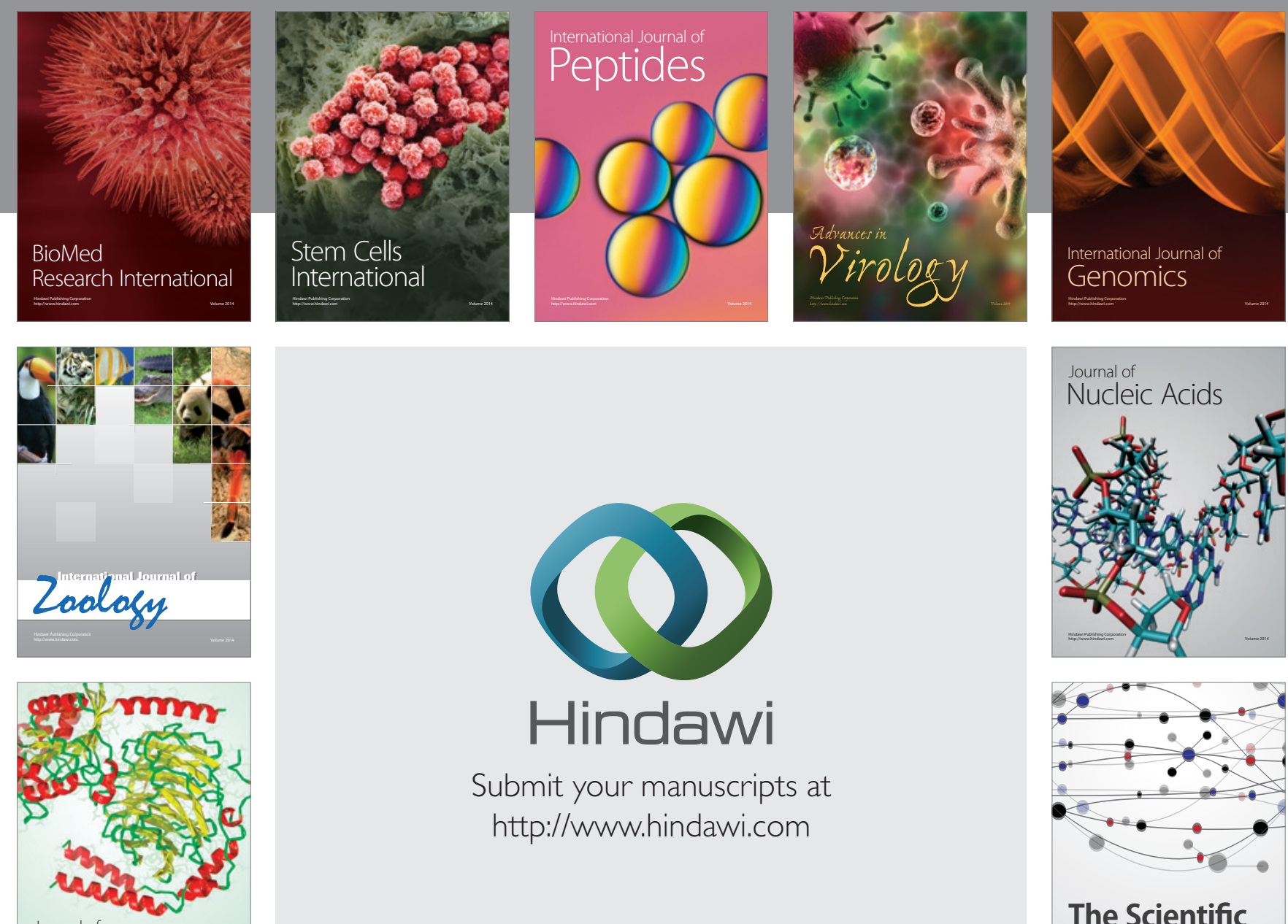

Submit your manuscripts at

http://www.hindawi.com

Journal of
Signal Transduction
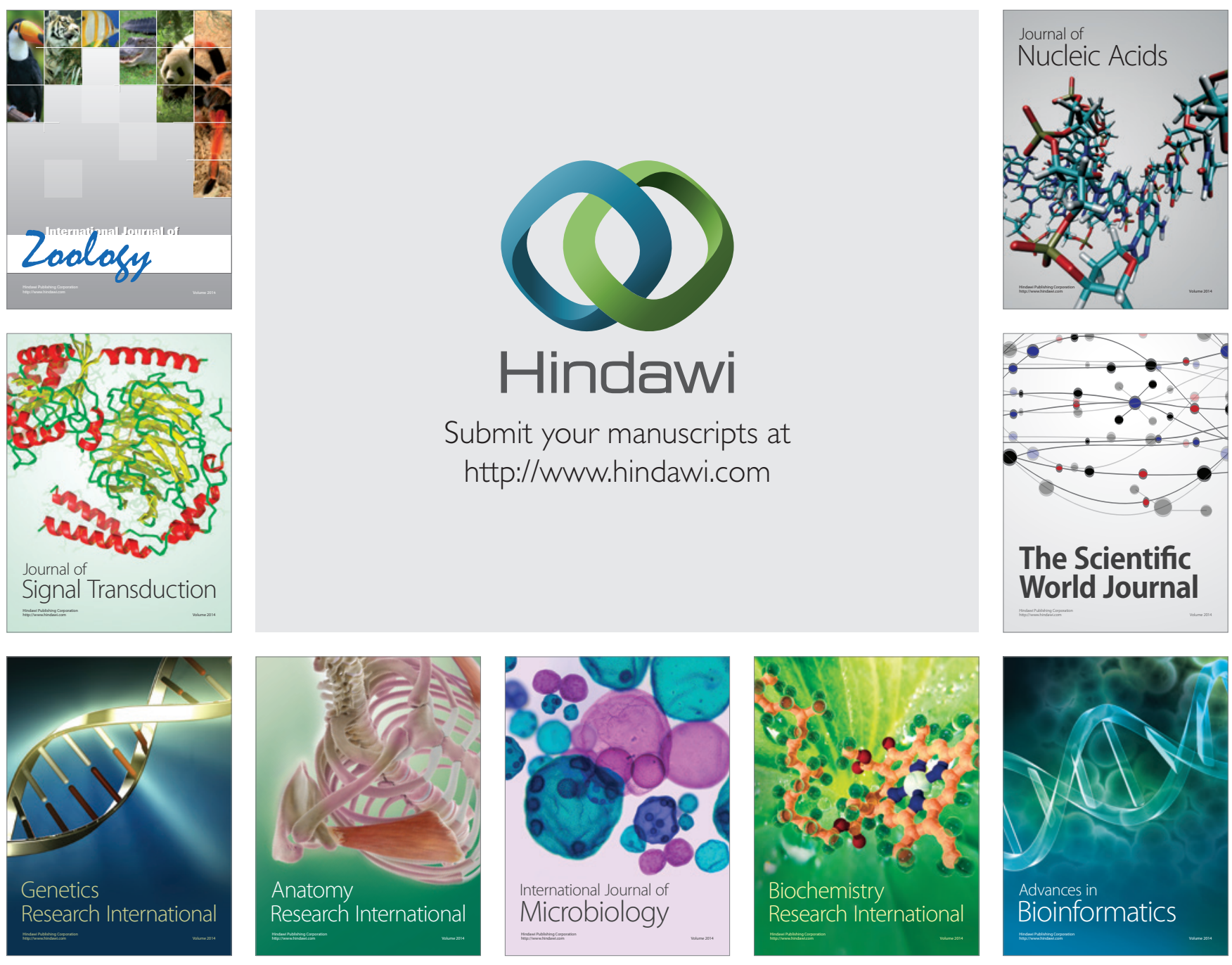

The Scientific World Journal
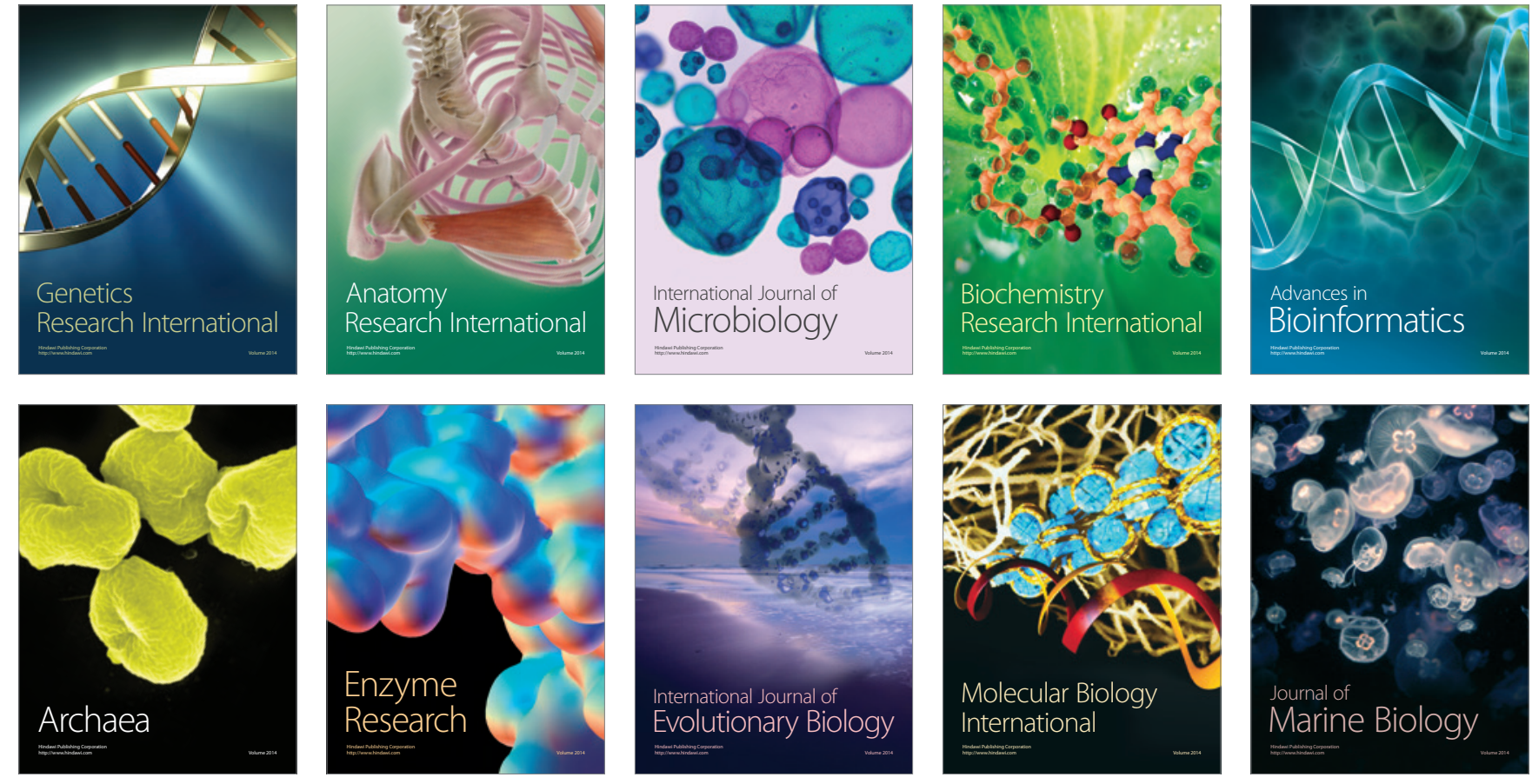